\section{$\underset{\text { hommes }}{\text { \& migrations }}$}

\section{Hommes \& migrations}

Revue française de référence sur les dynamiques

migratoires

$1313 \mid 2016$

1983 , le tournant médiatique

\title{
Hassan Ben Mohamed, La Gâchette facile
}

En collaboration avec Majid el Jarroudi, avant-propos de Toumi Djaïdja, Paris, Max Milo, 2015, 292 p., 18,90€

\section{Mogniss H. Abdallah}

\section{(2) OpenEdition}

\section{Journals}

Édition électronique

URL : http://journals.openedition.org/hommesmigrations/3605

DOI : 10.4000/hommesmigrations.3605

ISSN : 2262-3353

Éditeur

Musée national de l'histoire de l'immigration

Édition imprimée

Date de publication : 1 janvier 2016

Pagination : 169-170

ISBN : 978-2-919040-34-6

ISSN : $1142-852 X$

Référence électronique

Mogniss H. Abdallah, "Hassan Ben Mohamed, La Gâchette facile », Hommes \& migrations [En ligne],

1313 | 2016, mis en ligne le 17 juin 2016, consulté le 24 septembre 2020. URL : http://

journals.openedition.org/hommesmigrations/3605; DOI : https://doi.org/10.4000/

hommesmigrations.3605 


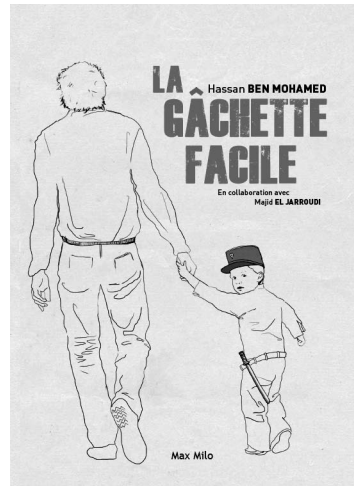

\section{Hassan Ben Mohamed}

La Gâchette facile

en collaboration avec

Majid el Jarroudi,

avant-propos de Toumi

Djaïdja, Paris, Max Milo, 2015, 292 p., 18,90€

Le 18 octobre 1980 , veille de l'Aïd el Kébir, Lahouari Ben Mohamed, Français d'origine marocai-

ne âgé de 17 ans, et trois de ses amis subissent un contrôle routier dans les quartiers Nord de Marseille. Les " minots " sont en règle. Mais un CRS grommelle " ce soir j'ai la gâchette facile ", persiste à fouiller la boîte à gant avec le canon de son pistoletmitrailleur Mat 49, une arme de guerre. Puis tire. Lahouari est tué sur le coup. De la cité des Flamants à la Canebière, c'est l'émoi. Les habitants, en particulier les mamans et les jeunes, manifestent avec vigueur contre cet énième " crime raciste » ou " sécuritaire».

Afin de le préserver du tumulte, le petit frère Hassan, 4 ans, est un temps éloigné par sa famille. Mais, de retour à la maison, il continue à s'interroger sur l'absence de son frère et sur l'agitation ambiante. Peu à peu, il apprend, seul, ce qui s'est passé. Ainsi, au collège, en plein cours, il ouvre son livre d'histoire et tombe sur une photo avec le portrait de son frère, brandi lors de l'arrivée de la Marche pour l'égalité et contre le racisme le 3 décembre 1983 à Paris.

Après son service militaire, Hassan Ben Mohamed entre dans la police, d'abord comme ADS (adjoint de sécurité) en
1999 puis, plus tard, dans une brigade anti-criminalité (BAC), il se familiarise avec l'état d'esprit qui règne « de l'autre côté » et se rode aux techniques de l'enquête-investigation. À l'intérieur même de l'institution policière, il entend à nouveau parler de la nuit du drame.

En 2010, la venue d'un journaliste télé pour interviewer sa mère va provoquer un déclic : "Pourquoi sont-ce toujours les autres qui racontent notre histoire et qui finissent par en disposer comme bon leur semble? " II se met alors en tête de la reconstituer, commence par consulter les archives familiales conservées par sa mère, ce qu'il n'avait pas osé jusque-là. Il apprend aussi que des amis de Lahouari avaient monté en son hommage une pièce de théâtre, "Ya Oulidi (Ô mon Fils) ", mais qu'ils n'en ont pas gardé de trace écrite. Il se lance dès lors dans sa propre enquête, bien décidé à en faire un livre, avec le soutien de son cousin entrepreneur, Majid El Jarroudi, et collecte toutes sortes de documents audio, vidéo, écrits ou photographiques. Son enquête va durer cing ans, ponctuée par l'organisation d'événements publics qui lui donnent une plus grande assurance. II rencontre les différents protagonistes, croise les témoignages concordants des témoins, jeunes ou policiers. II effectue des recherches dans des archives privées ou publiques, sollicite de nombreux acteurs impliqués dans l'effervescence sociale, judiciaire, politique ou culturelle suscitée par l'affaire jusqu'au procès du CRS à la gâchette facile, condamné en 1987 à dix mois de prison dont quatre avec sursis, peine assortie d'une amnistie. II 


\section{LIVRES}

y a matière à un document multimédia. Mais, par trop impatient, Hassan Ben Mohamed se concentre sur l'écriture. Variant les formes narratives, sans pathos excessif ni fioritures de style, il retrace l'évolution de son enquête jusqu'à... son éprouvante rencontre avec le meurtrier.

Au-delà du témoignage introspectif et de son intime conviction selon laquelle les tirs ont été délibérés et que justice n'a pas été rendue, l'auteur nous invite ainsi à une réflexion rare sur les limites de l'entre-soi, bousculant des mémoires lacunaires voire défaillantes, y compris dans les milieux " militants" concernés, mais il nous invite aussi à reconsidérer l'importance des dynamiques intra-familiales dans la constitution et la préservation de la mémoire collective.

Mogniss H. Abdallah

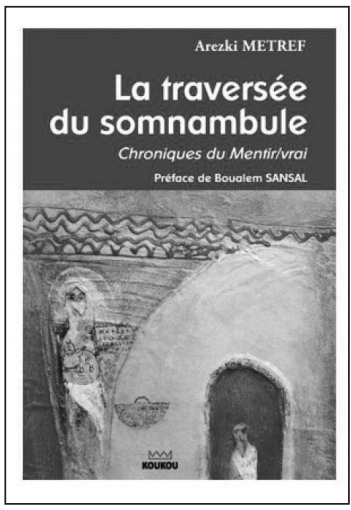

\section{Arezki Métref}

ta Traversée

dusomnambule.

Chroniques

dumentir-vrai

Préface de Bouratem

Sansal,Alger,

Koukou, 2015, 196p.

Journaliste, Arezki Mé tref appartient ì cette génération qui- a bai gnédansles heures encore ensoleillées de la dictature algérienne, distribuée en courant alternatif, tantêt incongru, tantôt ennuyeux ou monstrueux. Avec d'autres, en l'oceurrence avec Tahar Bjaut et Abdelkrim Diand, il participa, au tournant de la décennie 1990, ì l'émergence d'" une société civile moderne "commel'écritle préfacier, ici z̀lacréation d'une presse en rupturedunom de l'heb do créen janvier 1993 - avec le journalisme de papa. Ojaout assassiné, Métref part en France. Reste eette "société civile "et les mots de
Sansal, vite oubliés ici : "Qu'aurait elle fait sila grande Europe et la puissante Amérique avaient choisi de l'aider, elle, plutôt que le pouvoirmilitaire et les ista mistes? Mais voilà, grandeur et puis sance n'empêchent pas la myopie.".

Ahétrefest aussiun écrivain, adepte de ta nouvelle, du roman, de la poésie-ou del'écriture thêtrale. Ce recueilillustre ì merveille combien notre homme-st d'abord un littéraire. Le titre déjì. Ces ehroniques données au soir d'Algérie se nomment les "Chroniques du men tir vrai ", ce quiconduit d'entrée ì Ara gon. Quoi de mieux que les entrailles de la fiction, où mijotent indistincts vérités et mensonges, pour traduire la complexité d'une époque ou les sub tilités d'une âme, rendre visible l'invi sible, audible l'indicible, déposer ses tripes sur la table et faire-entendre le bruit et la fureur du monde. S'il fallait s'en convaincre, l'élogieuse préface du grand Sansal finirait d'aiguiser lacuriosité des moins pressés. Oui, la langue de Aétref est superbe- légère, vive, 